\title{
GESTÃO DA PROPRIEDADE INTELECTUAL NA UNIVERSIDADE PÚBLICA BRASILEIRA: DIRETRIZES PARA LICENCIAMENTO E COMERCIALIZAÇÃO
}

Asa Fujino 1

Eva Stal 2

Resumo: Este trabalho propôs-se a discutir a gestão da propriedade intelectual na universidade pública brasileira, principalmente no que se refere às estratégias para comercialização ou licenciamento dos direitos de exploração de resultados de pesquisas acadêmicas, identificando, na literatura internacional, as principais estratégias adotadas e recomendadas pelos escritórios de transferência de tecnologia das universidades estrangeiras e comparado-as com as práticas adotadas pelas universidades brasileiras, propondo, ao final, recomendações às instituições brasileiras.

Palavras-chave: Patente. Escritórios de transferência de tecnologia. Comercialização. Licenciamento. Universidade Pública. Resultados de pesquisa acadêmica.

\section{INTRODUÇÃO}

A necessidade crescente de conhecimentos científicos para alcance do progresso técnico, aliada ao encurtamento do ciclo tecnológico das inovações, vem exigindo dos atores envolvidos no processo de geração e difusão de inovações esforços no sentido de intensificar as práticas de cooperação tecnológica. A literatura internacional é abundante na abordagem do tema e na análise de diversos aspectos envolvidos na discussão, dentre estes, a tipologia das estruturas de interface, as dimensões da interação, as motivações e benefícios, as razões de sucesso, as barreiras e obstáculos (VALENTíN, 2002). 0 argumento da "Hélice Tripla", no qual governo, universidade e empresa se unem em prol do desenvolvimento tecnológico nacional, tem sido amplamente utilizado para convencer a universidade a cooperar com o setor privado (DAGNINO, 2003).

0 foco de discussão inicial girava em torno e um possível antagonismo entre a missão da universidade e a apropriação econômica do conhecimento por ela própria (FUJINO; STAL; PLONSKI, 1999). Superada essa fase, as universidades se conscientizaram da necessidade de proteger 0 conhecimento, via patentes, para que os resultados da pesquisa cheguem ao mercado e, sobretudo, para decidir a quem e como licenciar os direitos de exploração, pois, não sendo produtoras nem fornecedoras de serviços, não lhes compete explorar, por si só, tais resultados.

No Brasil, o aumento da consciência sobre a necessidade de transferir à sociedade os resultados da pesquisa financiada com recursos públicos não tem sido acompanhado por ações que viabilizem essa transferência. A questão é conceitual, com impactos na operacionalização de uma política clara sobre a questão. Um bom resultado de pesquisa não é suficiente para iniciar o processo de comercialização, é preciso demonstrar que é possível transformá-lo em inovação. 0 registro da patente é condição necessária para garantir autonomia no processo de licenciamento, mas insuficiente

\footnotetext{
${ }^{1}$ Cursos de Ciências da Informação, Comunicação e Artes, USP, São Paulo, SP. E-mail: asfujino @usp.br

2 Programa de Mestrado em Administração, UNINOVE, São Paulo, SP. E-mail: estal@uninove.br.
} 
para o sucesso da transferência, que pressupõe a absorção, pela empresa, do conhecimento gerado na universidade. Isso requer o empenho de ambas as partes para que ocorra "mais que um bom contrato, um encontro de mentes." (ALLEN, 2000, p. 3).

A cultura organizacional das universidades públicas brasileiras é sustentada, de um lado, por valores ideológicos que defendem o acesso irrestrito aos resultados de toda pesquisa desenvolvida e, de outro, por normas que mantêm uma hierarquia administrativa burocrática, balizada por marcos regulatórios de interpretações dúbias. A parceria com a empresa está no centro do debate sobre a propriedade intelectual na universidade e sobre a necessidade de uma legislação que regulamente as relações entre os setores público e privado quanto à transferência de tecnologia. Há, também, divergências em relação à responsabilidade pela transferência de tecnologia: alguns defendem que cabe à universidade estabelecer as diretrizes e estratégias para a operação e outros acreditam que a análise dos aspectos comerciais e de produção compete à empresa (GRANOWITZ, 2004). Caberá a universidade detentora da tecnologia a decisão final sobre a transferência. Por isso, é importante que ela esteja preparada para uma negociação que atenda a seus interesses financeiros e preserve sua missão social.

Assim, o problema desta pesquisa foi definido com base nesse contexto cultural. Uma vez compreendida e aceita a necessidade de transferência dos resultados da pesquisa acadêmica para a geração de inovações pelas empresas, surge a questão: como realizar tal processo com eficiência, eficácia e ética, estabelecendo critérios para licenciamento e comercialização, com vistas a beneficiar a sociedade e impedir que a patente seja utilizada apenas para proibir sua exploração por terceiros?

\section{PROCEDIMENTOS METODOLÓGICOS}

A pesquisa, qualitativa e de caráter descritivo, procurou identificar as principais questões abordadas na literatura internacional recente para compor o quadro referencial e o panorama das estratégias desenvolvidas por universidades americanas, européias e asiáticas, a fim de compará-las com as práticas adotadas por universidades brasileiras.

A pesquisa descritiva apresenta um fenômeno ou situação mediante a um estudo realizado em determinado espaço-tempo. Neste trabalho, buscou-se a descrição das características de determinado fenômeno (o processo de licenciamento e comercialização dos resultados de pesquisa) e 0 estabelecimento de relações entre variáveis, levantando as opiniões, atitudes e crenças dos responsáveis pelo fenômeno.

Os procedimentos metodológicos incluíram a utilização de fontes primárias, como entrevistas e pesquisas documentais, e secundárias, como pesquisa bibliográfica, análise de documentos oficiais e consulta aos portais de universidades estaduais e federais selecionadas entre as que participam do projeto FINEP "Escritórios de Assessoria Tecnológica - EATs": Universidade de São Paulo (USP), Universidade Estadual de Campinas (UNICAMP), Universidade Federal de São Carlos (UFSCar), Universidade Federal de São Paulo (UNIFESP), Universidade Federal do Rio de Janeiro (UFRJ), Universidade Federal do Rio Grande do Sul (UFRGS). A Universidade Federal de Minas Gerais (UFMG) e a Universidade Federal de Pernambuco (UFPE) foram consultadas, mas não responderam.

Para efeito de comparação, foram incluídos três institutos de pesquisa cuja missão básica é a transferência de tecnologia: Instituto de Pesquisas Energéticas e Nucleares (IPEN), Instituto de Pesquisas Tecnológicas do Estado de São Paulo (IPT) e Fundação Oswaldo Cruz (FIOCRUZ).

As entrevistas com os responsáveis pelos escritórios de transferência de tecnologia destas instituições foram presenciais e virtuais, semi-estruturadas, com as mesmas perguntas feitas a todos os entrevistados, os quais podiam também incluir observações e relatos de suas experiências acerca do processo pesquisado. 
A pesquisa procurou responder às seguintes questões:

- Qual a relação entre as atividades dos escritórios de transferência de tecnologia em instituições acadêmicas e as políticas de governo referentes ao desenvolvimento científico, tecnológico e industrial?

- Qual a relação entre a instituição acadêmica e a unidade responsável pela transferência de tecnologia? Como a cultura predominante na instituição afeta a operacionalização do escritório de transferência de tecnologia?

- Qual a estrutura organizacional mais adequada, interna ou não à universidade?

- A quem compete a administração dos escritórios? Quais as funções e o perfil da equipe responsável?

- Como são definidas as estratégias de marketing e negociação? Quais são as ações dirigidas ao público interno e ao público externo à universidade?

- Quais são os critérios de busca e seleção de potenciais parceiros? Como é garantido o sigilo nos contratos?

- Como são definidas as estratégias de comercialização? Quais os critérios para definir a forma de licenciamento e o estabelecimento de preço e/ou royalties?

- Existe uma política explícita de remuneração ao pesquisador e à equipe responsável pelas ações de transferência de tecnologia?

\section{REFERENCIAL TEÓRICO}

O objetivo da política de patentes de uma universidade é alcançar um equilíbrio entre as necessidades dos inventores, daqueles que vão desenvolver a invenção, da instituição, dos patrocinadores da pesquisa e do público em geral. Na transferência de tecnologia, o foco são os resultados da pesquisa científica e os aspectos de licenciamento e comercialização. Para Ben-Ami (2000), em geral, as opções estratégicas de um titular da patente incluem:

a) exploração própria da patente;

b) o uso da patente para impedir sua exploração por terceiros;

c) transferência dos direitos a terceiros mediante compensação financeira;

d) a concessão de licença a terceiros;

e) o uso da patente na constituição de uma nova empresa (start-up).

Na universidade, apenas as três últimas opções são viáveis. Nas opções (c) e (d), a maioria das políticas exige que a empresa licenciada envide todos os esforços para comercializar uma patente sem fazer uso "defensivo", mantendo a invenção fora do mercado para que não concorra com um produto em uso. Se isso ocorrer, a licença é cancelada e a universidade readquire os direitos sobre a patente (march-in rights). Na negociação de licenças oriundas da universidade, há um aspecto fundamental a se discutir: o estabelecimento de critérios tanto para a valoração da tecnologia quanto para a decisão sobre o tipo de licença que será concedida. 


\subsection{AVALIAÇÃO DE TECNOLOGIA}

O sucesso da negociação depende, em grande parte, da capacidade do licenciador de fazer 0 licenciado compreender o real valor da tecnologia. Para Watanabe et al. (2004), esse valor pode ser medido pelo fluxo total de caixa que ela gerará através de sua futura utilização. Todavia, quando resulta de pesquisa acadêmica, é difícil para o licenciador demonstrar seu valor econômico. Ela deve ser diferenciada dos demais bens de consumo, produtos ou serviços pelo grau de visibilidade e de agregação de valor. Para evitar julgamentos incorretos, propõe-se que a estratégia de marketing foque o plano de negócio e que a produção de protótipos mostre como a tecnologia será efetivamente incorporada.

Esses aspectos são ressaltados no manual de orientação do Valuate 2000 - Programa da AUTM - Association of University Technology Managers (www.autm.net) - para auxiliar os escritórios de TT a calcular valores para licenciamento e taxas de royalties. Uma das orientações é conscientizar 0 licenciador (universidade) de que o valor adequado é aquele com que licenciado e licenciador concordam. Nenhum comprador pagará por despesas anteriores de pesquisa e não há fórmulas adequadas para se chegar a um valor que represente os investimentos na formação dos pesquisadores até o momento da "invenção". Os resultados de pesquisa requerem substancial desenvolvimento antes de chegar à produção e distribuição. A universidade participa apenas da primeira fase de um longo processo, até que este seja viável economicamente. Os principais fatores que afetam a avaliação da invenção são:

- o potencial de mercado;

- como a tecnologia se ajusta ao licenciador em termos do portfolio de tecnologias, abrangência de mercado, capacidade de manufatura e canais de distribuição;

- se o produto abrirá novos mercados para o licenciado ou se vai apenas acrescentar algo no mercado atual. O tempo necessário para o desenvolvimento da tecnologia, os custos de manufatura e distribuição em relação às tecnologias correntes;

- os benefícios da nova tecnologia frente à tecnologia corrente no mercado pretendido, a existência de tecnologias alternativas em andamento e de outras patentes relacionadas;

- o potencial de novas oportunidades decorrentes da aplicação em múltiplos campos.

No processo de transferência de direitos a terceiros, algumas universidades se colocam na perspectiva do comprador, tentando entender como a empresa tomará sua decisão. Para isso, utilizam estudos de viabilidade técnico-econômica e de mercado. Eventualmente, podem ser usados métodos de avaliação de tecnologia como base para estabelecer preços mínimos. No primeiro caso, busca-se compreender os desafios técnicos implícitos no desenvolvimento da tecnologia e os investimentos que a empresa terá que fazer para viabilizá-la comercialmente. No segundo, procura-se conhecer 0 potencial de mercado para a tecnologia, considerando o estado da arte e eventuais concorrentes. No terceiro, o objetivo é conhecer as variáveis implícitas na tomada de decisão por parte da empresa. (DI GIORGI, 2004; GRANOWITZ, 2004).

Yu; Azevedo (2000) classificam os métodos de avaliação de tecnologia em quatro grupos: clássicos, utilizados para ordenar projetos segundo critérios de prioridade; financeiros convencionais, baseados na análise de fluxo de caixa de investimento; os fundamentados na Teoria da Decisão, que trata formalmente as incertezas, as decisões seqüenciais, os objetivos múltiplos e a atitude em relação ao risco, e os de programação matemática, que consideram a interação entre os projetos da carteira. Há, ainda, outros métodos como os cognitivos, os de análise de clusters e de diagrama de bolhas. 
Entretanto, há ressalvas quanto ao uso de técnicas analíticas, pois estas não consideram as emoções, os desejos e a lealdade das pessoas, aspectos esses que podem influenciar as decisões.

\subsection{VALOR ECONÔMICO DA PATENTE}

Vários autores têm desenvolvido modelos, baseados em diferentes parâmetros, que levam à valoração econômica da patente. Os parâmetros mais considerados são: a análise do tempo de vida, que considera retornos marginais decrescentes; a abrangência em relação às reivindicações; a atividade inventiva embutida; a revelação de informações técnicas (disclosure); a dificuldade de invenção no seu entorno; a posição no portfolio ao qual a patente pertence; a variedade de usos ou funções e o potencial de uso como patente defensiva e como mercadoria de intercâmbio com concorrentes (REITZIG, 2003).

Sherry; Teece (2004) alertam para a possibilidade de mudança, às vezes em curto espaço de tempo, do valor de uma inovação, distinguindo-o dos direitos de propriedade intelectual associados a esta. No primeiro caso, o valor muda conforme o ciclo de vida da inovação, que pode se tornar obsoleta em função de outra. No segundo, do ponto de vista legal, há vários estágios na evolução de uma patente e a cada estágio está associado um valor. Embora não haja mudanças técnicas entre as fases de solicitação de registro, de aceitação da patente e de publicação da carta-patente; do ponto de vista econômico há grande alteração, pois ela pode ser a patente que dará origem a uma família de novas patentes. Para esses autores, as negociações devem considerar o potencial de incerteza quanto à obtenção da patente, incluindo a possibilidade de pagamento de caros processos de litígio.

Embora tais métodos possam ser úteis na compreensão do valor da tecnologia, sua aplicação é complexa para a universidade, pois esta nem sempre pode contar com o suporte de especialistas para tais estudos. Por outro lado, para a universidade, a questão não está em garantir o melhor preço, a melhor negociação do ponto de vista financeiro ou o retorno do investimento realizado. Sua preocupação principal não é ganhar dinheiro, há outros aspectos na pesquisa que fazem parte da sua própria missão, dentre eles, a capacitação de recursos humanos, a busca de conhecimento e o desafio de superar o estado da arte. A lógica da universidade é baseada na oferta, ao passo que a decisão pelo registro, ou não, de uma patente deve ser baseada em critérios comerciais e de demanda; portanto, são também esses os critérios que devem ser considerados na comercialização. $O$ escritório de licenciamento de tecnologia da Universidade Hebraica de Jerusalém pode recusar algo brilhante em termos científicos se não vislumbrar aplicação para tais resultados, deixando claro para o pesquisador que o objetivo é comercial (BEN-ISRAEL, 2000).

\subsection{CRITÉRIOS PARA LICENCIAMENTO}

Nas universidades públicas brasileiras, tal discussão é mais complexa em função da cultura acima referida e das interpretações de uma legislação que não contempla claramente a questão da comercialização da tecnologia resultante de pesquisas financiadas com recursos públicos. Uma das quais indica a necessidade de licitação da patente quando a titularidade é exclusiva da universidade. Essa exigência é considerada absurda, pois expõe a tecnologia e os interessados em adquiri-la, tornando inviável a participação de empresas de setores mais competitivos (JC, 2003). Assim, aguardase a aprovação do projeto da Lei de Inovação que deverá abolir tal exigência para os casos de licenciamento não exclusivo, mantendo, ainda, a exigência de chamada pública para os casos de licenças exclusivas. Nesse cenário, é importante que a universidade procure se proteger das 
acusações de privilegiar determinada empresa e é fundamental que suas ações junto ao potencial cliente sejam regidas por uma política transparente, com diretrizes e critérios claros para licenciamento e comercialização.

Quando a universidade for detentora única da titularidade, tais critérios deverão nortear a decisão para cada tipo de licença concedida à empresa. A decisão envolve a análise de oito variáveis combinadas: exclusividade; não exclusividade; aplicação geral; aplicação por área específica; pagamento de royalties; não pagamento de royalties; direito de sublicenciar; sem direito de sublicenciar. A decisão mais difícil é avaliar situações em que o licenciamento exclusivo se faz necessário. Um dos critérios é avaliar o estágio de maturação da pesquisa, quanto maior a necessidade de desenvolvimento, mais caro será o investimento e maior o risco de fracasso. Nesses casos, a empresa só aceitará negociar a licença exclusiva. Um estudo realizado em 62 universidades americanas mostra que $45 \%$ das invenções referem-se a "prova de conceito" (proof of concept), em que o fracasso é da ordem de $72 \%$. Para a universidade, por outro lado, muitas dessas invenções são ferramentas de pesquisa cuja exclusividade pode limitar seu uso por futuros pesquisadores. Nesse sentido, a análise da relação custo/benefício deve envolver critérios outros, além do financeiro, e o acordo deverá, necessariamente, prever a possibilidade de seu uso, pela universidade, para fins acadêmicos e de pesquisa (THURSBY; THURSBY, 2003).

Quando os resultados são provenientes de pesquisa financiada por empresas ou em parceria universidade-empresa, a titularidade da patente poderá ser de propriedade única e exclusiva da empresa, de ambas ou da universidade. No primeiro caso, aquela se compromete a ceder a esta uma licença sem ônus e não exclusiva de tais resultados desde que a universidade os utilize unicamente em suas próprias pesquisas ou para fins didáticos.

Segundo a legislação americana, a posse total da propriedade intelectual cabe à empresa em algumas situações específicas: quando ela fez investimento significativo no desenvolvimento da tecnologia resultante da pesquisa universitária; quando ela é o único usuário das invenções resultantes, ou se repassou informações proprietárias, tecnologia ou materiais que tenham constituído a base da pesquisa. Em geral, nas pesquisas realizadas com recursos parciais ou globais de empresas ou agentes financiadores, a estes caberá um percentual sobre os resultados que sejam patenteáveis, em proporções discutidas caso a caso. A exploração comercial também será avaliada individualmente (STAL; SOUZA NETO, 1998).

A titularidade conjunta, comum nos contratos das universidades brasileiras, não é bem aceita na comunidade internacional. Há o entendimento de que é importante definir quem tem o maior percentual, pois, em caso de litígio, o licenciamento para uma terceira parte implicará em maiores dificuldades se houver dois proprietários envolvidos. Alguns especialistas recomendam não conceder licenças exclusivas ou transferir direitos sobre resultados de pesquisa em temas centrais de grande abrangência (STAL, 1995). A alternativa para não comprometer sua liberdade de ação futura é conceder licenças não-exclusivas, com ou sem pagamento de royalties, pois essa é a forma mais condizente com 0 objetivo de promover a ampla disseminação dos produtos da universidade. Entretanto, algumas universidades já trabalham com licenças exclusivas, reconhecendo que certas tecnologias não serão desenvolvidas a menos que as empresas tenham assegurado um período de utilização exclusiva, durante o qual possam obter o retorno financeiro de seu investimento.

As universidades também consideram interessante a concessão de licenças exclusivas por campo de utilização, que restringem a exploração comercial a determinado setor ou região, permitindo desenvolver a tecnologia em áreas não relacionadas ao negócio principal de seu licenciado. A tendência é garantir à universidade os direitos de titularidade e à empresa os direitos de exploração comercial, via contrato em que a última tenha o direito de preferência garantido por cláusula específica. É improvável que uma universidade venda uma invenção patrocinada por uma empresa à outra, logo, a firma patrocinadora não terá negado seu direito à licença (FUJINO; STAL; PLONSKI, 1999). Considerando que grande parte da pesquisa patrocinada não resulta em invenções patenteáveis, a 
maioria das universidades americanas tenta evitar a inclusão de cláusula relativa a direitos dos patrocinadores nos contratos. Preferindo negociar licenças apenas depois que houver uma invenção, 0 que simplifica a assinatura dos contratos e permite negociações posteriores mais focadas (MATKIN, 1990).

As opções de licenciamento, no caso de a universidade ser a titular, são:

a) Concessão de opção para uma licença: há um período durante 0 qual o patrocinador tem 0 direito de optar por uma licença para exploração futura. Isso porque, muitas vezes, ao final do contrato, não há informações suficientes para que ele tome uma decisão. A duração do período de opção varia. Em geral, as universidades preferem que ele seja curto, o que lhes permite buscar uma terceira parte caso o patrocinador não se interesse pela licença. Já este prefere um tempo maior para melhor avaliar o potencial comercial da propriedade intelectual.

b) Concessão de uma licença: em alguns casos, o contrato de pesquisa concede uma licença específica ao patrocinador para utilizar a propriedade intelectual, definindo a abrangência do uso. Isto é diferente da opção anterior, na qual a empresa não tem direitos no presente. Em geral, a universidade entra com um pedido de patente e a empresa a reembolsa pelos custos incorridos. Outra possibilidade é de que estas despesas sejam abatidas do pagamento de royalties à universidade.

c) Direito de primeira recusa: se o patrocinador decide exercer seu direito de opção, ele irá negociar uma licença dentro de certo período. Se, nesse tempo, não houver um acordo aceitável para ambos, a universidade poderá negociar o licenciamento da propriedade intelectual com terceira(s) parte(s). Porém, se ao final das negociações, houver um acordo em termos mais favoráveis do que aqueles oferecidos ao patrocinador, a universidade terá que oferecer a ele uma licença nesses termos e, em caso de interesse, ele obterá a licença, e não a terceira parte. Para a empresa, este direito é necessário para reduzir o risco de a universidade iniciar prematuramente negociações com uma terceira parte. Algumas universidades não aceitam essa cláusula, pois pode impedi-las de atrair novos interessados (STAL; SOUZA NETO, 1998).

\subsection{EMPRESAS NOVAS (START-UP FIRMS)}

Uma das dificuldades no licenciamento de projetos acadêmicos à indústria reside no fato de as pesquisas serem de caráter preliminar (seed stage) e exigirem maior tempo de desenvolvimento. Uma das alternativas para promover a criação de novos produtos resultantes da pesquisa acadêmica consiste no estabelecimento de empresas novas (start-up) com a ajuda de capital de risco (venture capita). Entre as vantagens estão: o financiamento maior da pesquisa inicial; decisões mais rápidas e o fato de os pesquisadores receberem ações da nova companhia. As desvantagens são: 0 risco de concessão de licença à empresa inexperiente; limitação de recursos; dificuldade de recursos humanos para P\&D\&E e para administrar a nova empresa; a possibilidade de fusão ou venda da empresa a terceiros e os eventuais conflitos de interesses entre acionistas e o conselho de diretores (BEN-AMI, 2000).

Quando as empresas já estão consolidadas e gerando tecnologias com potencial aplicação comercial, os desafios são similares aos da universidade: tentar comercializar tecnologias promissoras 
sem estrutura e experiência para identificar os mercados mais apropriados.

Gregório; Shane (2003) pesquisaram dez universidades americanas com o objetivo de identificar as razões que levam uma universidade a gerar mais empresas do que outras. $O$ estudo considerou os seguintes aspectos: a disponibilidade de capital de risco na área próxima à universidade; a orientação comercial da pesquisa; sua qualidade intelectual; as políticas dos escritórios de TT quanto a investimentos nas empresas start-up e compartilhamento de royalties com 0 inventor. Os resultados mostram que os dois últimos aspectos são fundamentais para o aumento da criação de novas empresas.

No caso brasileiro, a experiência tem demonstrado que a principal barreira para o surgimento de empresas inovadoras (start-ups) é a atual legislação, que garante à instituição de pesquisa a titularidade sobre a patente e impede que o pesquisador crie uma empresa para explorar o resultado de sua própria invenção (REINACH, 2004).

\subsection{PRÁTICAS ADOTADAS E/OU RECOMENDADAS NA LITERATURA}

Em uma pesquisa sobre o processo de transferência de tecnologia entre a universidade e a indústria, Siegel et al.. (2003) entrevistaram quase uma centena de pessoas-chaves em escritórios de TT de cinco universidades americanas, em diferentes regiões. Nas entrevistas, foram incluídos empreendedores e especialistas em negócios. Identificaram-se numerosas barreiras, incluindo choques de cultura, inflexibilidade burocrática, sistema inadequado de remuneração e gestão ineficiente dos escritórios de TT. Entre as principais recomendações destacam-se:

- A universidade deve ampliar seu conhecimento sobre as necessidades das empresas que podem vir a comercializar sua tecnologia. Esse resultado é compartilhado por $75 \%$ dos entrevistados, e os autores observam que há certa "apreensão" entre os administradores das instituições acadêmicas, pois o ônus cabe à universidade. Um dos entrevistados sugere alguns questionamentos a serem feitos aos inventores:

- Por que alguém teria interesse em comercializar sua invenção?

- Você tem, de fato, um produto?

- Qual o seu objetivo e como pretende alcançá-lo?

- A universidade deve inteirar-se dos custos necessários para transformar uma invenção em inovação e estar ciente de que há "boas invenções" que são um fracasso comercial.

- É necessário que os objetivos e as metas sejam compartilhados em uma parceria. Mesmo que um objetivo seja mais importante para um do que para o outro, é preciso haver um acordo para que ambos trabalharem juntos na consecução desse objetivo.

- É necessária maior flexibilidade, por parte da universidade, no processo de negociação do licenciamento. Em geral, a universidade é criticada por defender agressivamente seus direitos de propriedade intelectual e falhar na concretização da idéia em inovação. Muitas universidades são extremamente conservadoras na negociação, preferindo maximizar royalties, mesmo que isso diminua as chances de concretização do acordo.

- A universidade deve adotar políticas e procedimentos mais racionais e flexíveis nos contratos de negociação para transferência de tecnologia, pois sua aversão a riscos é extremamente frustrante para empresas inovadoras (start-ups) e outras empresas que 
necessitam de resposta rápida para mudanças em um ambiente competitivo.

- Em relação aos recursos humanos, é importante contratar pessoas com habilidade em marketing e maior experiência na área de negócios.

- A eficiência dos escritórios de TT poderia ser estimulada pela adoção de remuneração por incentivos. Como os pesquisadores normalmente recebem royalties por tecnologias patenteadas e os funcionários dos escritórios recebem salário fixo, não há incentivos financeiros para que estes se empenhem na transferência de tecnologia. Com a adoção deste modelo, todos trabalhariam na consecução de objetivos comuns.

- A universidade deve empenhar mais recursos para os escritórios, principalmente para formação de equipes com pessoal qualificado para atividades de marketing. Um dos entrevistados argumenta que a presença de um ou dois funcionários em tempo integral, dedicados ao escritório de TT, numa universidade com 30.000 pessoas, mostra a pouca importância dada ao tema e à constituição de uma carteira adequada de tecnologias.

- A alta administração da universidade deve lutar para que a TT seja uma prioridade, destacando um líder para estabelecer os objetivos e as metas a serem alcançadas.

- Os pesquisadores e os administradores das universidades devem conscientizar-se de que o licenciamento e os royalties não são produtos finais. Há vantagens inerentes ao processo, que se referem aos relacionamentos, redes sociais e de trabalho que incluem 0 setor privado e que possibilitam novas formas de aprendizado para os pesquisadores. Alguns reconheceram, na entrevista, que a experiência com pesquisadores da indústria os transformou em melhores pesquisadores acadêmicos, pois passaram a olhar o problema de outra perspectiva, o que os ajudou a refinar seus experimentos.

Ben-Israel (2000) deixa claro que ao escritório de TT cabe cuidar dos assuntos comerciais. No primeiro contato com os pesquisadores, estes devem ser questionados sobre os recursos que deram origem à pesquisa, a participação de colaboradores de outras instituições e o estágio da pesquisa. Pois é a partir daí que o escritório poderá ter clareza sobre se existe, de fato, uma tecnologia patenteável ou se a universidade tem mesmo direito a essa patente. Saber perguntar ou saber definir que perguntas devem ser feitas em cada caso é a grande questão. Há algumas perguntas que não podem deixar de ser feitas ao pesquisador e outras, igualmente importantes, que devem ser feitas ao potencial cliente. Em geral, há duas questões que o escritório deve se fazer e que devem receber respostas claras:

a) Será que essa invenção pode ser patenteada?

b) Será que ela é comercialmente atraente?

A partir daí as perguntas consideradas mais relevantes são (BEN-ISRAEL, 2000.):

- Já publicou? Em que estágio a pesquisa se encontra? Tem colaborador de outro lugar?

- Recebeu bolsa ou financiamento de alguém a quem deva uma explicação?

- Quem são os inventores? São líderes reconhecidos nas suas respectivas áreas? Sabem quais as necessidades de mercado ou apenas inventam soluções para problemas inexistentes? Já tiveram outros sucessos? São cooperativos?

- O mercado já existe ou será preciso esperar que ele se desenvolva? Qual o seu tamanho? Quais os investimentos realizados nesse mercado? 
- O invento responde a uma necessidade atual ou a uma demanda que pode surgir daqui a alguns anos? Se for importante daqui a dez anos pode não ser inteligente registrá-la hoje, porque naquela ocasião a vigência da patente só terá mais dez anos.

- Quais serão as reivindicações desta patente? É uma patente de processo, em que depois será difícil saber quem a está utilizando, de uma molécula ou de um material?

- Qual a dinâmica nessa área? Quando conseguirmos a aprovação do registro, a patente já estará obsoleta?

Outro estudo, conduzido por Siegel; Waldman; Link (2003), partiu da hipótese de que a produtividade dos escritórios de TT depende das práticas organizacionais. Como não há medidas quantitativas disponíveis sobre essas práticas, os autores usaram método qualitativo para entrevistar 55 pessoas de cinco diferentes universidades americanas e concluíram que os fatores críticos são: 0 sistema de remuneração para os professores envolvidos no processo de TT, os benefícios e práticas de gestão da equipe, as ações por parte da administração para eliminar barreiras de informação e a comunicação entre a universidade e a indústria. 0 estudo mostra a necessidade de desenvolver, nos funcionários de escritórios de TT, habilidades de mediação essenciais ao relacionamento com os pesquisadores, provedores da tecnologia, empreendedores, empresas e compradores da tecnologia.

Com o objetivo de identificar as principais diferenças na interação em relação a grandes empresas já consolidadas e discutir o papel dos escritórios de TT nesse tipo de parceria, Shane (2002) estudou as quatro dimensões da colaboração entre universidades e empresas de base tecnológica. As dimensões consideradas foram: atividades de pesquisa contratada, consultoria, desenvolvimento tecnológico, licenciamento e comercialização de tecnologia. Os resultados obtidos revelam que tais empresas têm maior dificuldade de participar de consórcios; maior necessidade de fundos governamentais; preferem o apoio financeiro na forma de investimentos de capital; requisitam direitos de licença exclusiva; necessitam de um envolvimento maior da universidade na etapa posterior ao licenciamento da tecnologia, no que se refere à consultoria técnica; necessitam de financiamentos complementares para 0 desenvolvimento da tecnologia licenciada; necessitam de licenças com forte proteção intelectual, pois dependem do acesso à família de patentes e, finalmente, as taxas de royalties devem ser baixas. Tais constatações mostram que a universidade deve estabelecer políticas diferenciadas para licenciamento e comercialização de tecnologia para empresas de base tecnológica, além de apresentar uma postura mais flexível no relacionamento.

\section{ANÁLISE E DISCUSSÃO DOS RESULTADOS}

Conforme estabelecido nos procedimentos metodológicos, foram definidas algumas questões de pesquisa envolvendo a transferência de tecnologia das universidades e de institutos de pesquisa para empresas. Os resultados foram agrupados segundo aquelas questões.

\subsection{RELAÇÃO ENTRE AS ATIVIDADES DOS ESCRITÓRIOS DE TT EM INSTITUIÇÕES ACADÊMICAS E AS POLÍTICAS DE GOVERNO REFERENTES AO DESENVOLVIMENTO CIENTÍFICO, TECNOLÓGICO E INDUSTRIAL.}

A pesquisa demonstrou uma estreita relação entre as práticas adotadas pelas instituições no que se refere à TT e à política de Ciência, Tecnologia e Inovação de cada país. Esse resultado confirma a necessidade de um trabalho dinâmico entre os agentes da "hélice tripla" para viabilizar 0 
desenvolvimento tecnológico local, regional ou nacional. Assim, políticas de incentivo à cooperação UE deram origem a práticas mais homogêneas e bem sucedidas, a exemplo das instituições israelenses (Instituto Weizman de Tecnologia, Universidade Hebraica de Jerusalém) e americanas (Columbia University, Ohio University, Johns Hopkins University, University of Maryland, Massachusetts Institute of Technology, Stanford University, Colorado University, Cornell University, University of Michigan), nestes casos, após a implementação do Bayh-Dole Act (CHAMAS, 2001); e menos homogêneas entre as instituições de países com políticas recentes ou ainda em fase de implementação, a exemplo de Taiwan, com a Science and Technology Basic Law (CHANG, 2004) e do Brasil cuja Lei de Inovação está em fase de discussão.

Essa relação fica clara quando se examina o caso da Suécia, um país com a mais alta taxa de recursos aplicados em P\&D per capita, alto índice de produção científica e com fraco desempenho na cooperação com a indústria e na geração de empresas start-up. Diferentemente de nos EUA, na Suécia não há política de incentivos aos pesquisadores para transferência dos resultados de suas pesquisas (GOLDFARB; HENREKSON, 2003). Em alguns países, foram criados programas governamentais regionais que visam ao estabelecimento de uma organização para dar suporte à estruturação de escritórios de TT nas universidades, o que abre possibilidades de parcerias entre as instituições e evita a concorrência predatória entre elas. Alguns deles: Bayern Patent Die Bayerische Hoschschul-Patentinitiativen na Alemanha; British Technology Group no Reino Unido; Oficina de Transferência de Tecnologia na Espanha (CHAMAS, 2001). Mais recentemente, a University Intellectual Property Headquarters no Japão (KAMIJO; WATANABE, 2004; TAMAI; NISHIMURA, 2004) e a Regional Consortium of Technology Licensing Offices na Coréia do Sul (PARK, 2004). No Brasil, a ausência de uma legislação clara tem sido o maior obstáculo no que diz respeito à transferência de tecnologia para a indústria e ao trabalho de parceria entre as instituições, pois há diferentes interpretações sobre a necessidade de licitação nos casos de patentes registradas.

\subsection{RELAÇÃO ENTRE A INSTITUIÇÃO ACADÊMICA E O ESCRITÓRIO DE TRANSFERÊNCIA DE TECNOLOGIA. A INFLUÊNCIA DA CULTURA ORGANIZACIONAL SOBRE O DESEMPENHO DO ESCRITÓRIO. ESTRUTURA, FUNÇÕES E PERFIL DA EQUIPE RESPONSÁVEL.}

A cultura predominante na academia afeta profundamente os escritórios de transferência de tecnologia, uma vez que cabe à alta administração definir a política de operação dos escritórios e a sua estrutura organizacional, as quais terão impacto direto sobre a sua atuação. Assim, em países como Estados Unidos, Reino Unido ou Israel cuja cultura estabelece uma clara diferença entre o papel da universidade, como geradora e transmissora de conhecimento, e o do escritório de TT, como unidade de transferência e comercialização de tecnologia, os conflitos inerentes à decisão do que deve, ou não, ser patenteado e os critérios para licenciamento e comercialização foram resolvidos pela transferência dos direitos de propriedade industrial aos escritórios para que eles possam avaliar, proteger e comercializar com total autonomia.

Esses escritórios contam com uma equipe especializada em comercialização, que atua na identificação, seleção e monitoramento de oportunidades, até a fase final da transferência. Em geral, a redação das patentes é terceirizada e esses escritórios atuam, também, no apoio à criação de empresas start-up, potenciais licenciadas. Essa estrutura conta com orçamento composto por financiamentos e receitas dos contratos de TT. O Instituto Weizman conta com um fundo de capital de risco, formado por capital estrangeiro, que tem o direito exclusivo de primeira oportunidade com relação aos frutos da pesquisa desenvolvidos na universidade. O Contrato entre a companhia Yeda, a Universidade e o Fundo determina a participação acionária de cada um, bem como as normas para compartilhamento dos valores de financiamento e de royalties nos casos específicos (BEN-AMI, 2000). 
No Brasil, embora as universidades se preocupem com essa questão, os escritórios de TT ainda não conseguiram um nível de autonomia e de infra-estrutura adequado à operação. A cultura é fortemente defensiva em relação a parcerias com a indústria, dificultando a implementação de uma política de licenciamento e comercialização das tecnologias ali criadas. Em geral, os escritórios são unidades internas, com equipe de funcionários da própria universidade, que vivenciam no cotidiano 0 conflito de interesses entre a universidade e as empresas, o que os impede de assumir seu papel com independência. Essa estrutura também inviabiliza a remuneração mais adequada aos funcionários do escritório de TT, pois premia somente os inventores no compartilhamento dos royalties. A exceção é a UNICAMP, que reestruturou sua área de propriedade intelectual e adota uma política de comercialização agressiva. A experiência é recente e só foi possível com o apoio do atual reitor que, independentemente das discussões jurídicas em curso, contratou um profissional com experiência na área comercial, além de assumir a dispensa de licitação para o licenciamento de patentes, realizado por meio de uma fundação de apoio à pesquisa.

\subsection{ESTRATÉGIAS DE MARKETING E NEGOCIAÇÃO}

$\mathrm{Na}$ maioria das universidades estrangeiras, as ações são desenvolvidas em estreita colaboração com os inventores, que ajudam a identificar potenciais interessados. Essa parceria tem se mostrado bastante eficaz, pois se trata não só de identificar uma empresa que esteja disposta a pagar pelos direitos de exploração, mas que seja capaz de introduzir um novo produto no mercado, situação de alto risco, com taxas elevadas de fracasso. Outras estratégias envolvem: disponibilização de informações em portais da universidade, elaboração de casos de sucesso com inventores para divulgação interna e externa, promoção de reuniões e eventos visando atrair o público empresarial e contatos com associações empresariais. A arquitetura dos sites é, em geral, cuidadosa e reflete a preocupação de oferecer informações de interesse do empresário, inclusive normas e modelos de contratos, a exemplo da Johns Hopkins University (www.hopkinsmedicine.org) e da Universidade Hebraica de Jerusalém (www.yissum.co.il).

No quesito negociação, os escritórios estrangeiros, de modo geral, iniciam o processo com a apresentação de um resumo não confidencial que explica de forma ampla o que faz a tecnologia, sem especificar como. Na reunião, é assinado um acordo de confidencialidade e só quando há interesse claro da empresa é que se passa à fase seguinte, com 0 estabelecimento das condições de licenciamento. Também é comum que a empresa seja estimulada a assinar um acordo que prevê o financiamento para a pesquisa avançar até a fase de desenvolvimento.

No Brasil, estratégias similares começam a ser adotadas, mas além dos problemas culturais que dificultam o diálogo com os inventores, observa-se enorme distância entre os objetivos pretendidos pela política de marketing e as ações, caracterizadas pela prática da oferta sem o cuidado necessário com as características da demanda. Um Exemplo claro são os sites dos escritórios de TT das universidades: 0 acesso a eles, dentro do portal da universidade, é dificílimo, pois não há qualquer link nas páginas principais que permita ao interessado chegar às informações sobre patentes disponíveis. Além disso, como não há homogeneidade em relação às estruturas organizacionais universitárias, ora o escritório se subordina à Pró-Reitoria de Pesquisa, ora à de Extensão, ora a alguma Coordenadoria ou Fundação de Apoio, o que para 0 usuário externo se constitui num labirinto. 0 caminho da acessibilidade virtual é desanimador e, do ponto de vista cognitivo, quase intransponível.

A dificuldade de acesso às páginas da Internet reflete a cultura acadêmica fundamentada naquilo que a universidade julga poder oferecer à sociedade, sob forma compreensível para seus pares. Quanto aos procedimentos administrativos e legais, observou-se a preocupação atual das universidades, como UFRJ, UNICAMP e UFRGS, e, principalmente, dos institutos de pesquisa, como o 
IPT, com a adoção de um termo de confidencialidade no início das discussões e a elaboração de modelos de contratos mais flexíveis, adaptáveis a cada caso.

\subsection{ESTRATÉGIAS DE COMERCIALIZAÇÃO: A BUSCA DE PARCEIROS POTENCIAIS, A QUESTÃO DO SIGILO E AS FORMAS DE LICENCIAMENTO.}

Em geral, as universidades estrangeiras seguem critérios similares para definir a forma de licenciamento e para estabelecer e preço e/ou royalties, sendo a licença exclusiva reservada aos casos em que a empresa deverá investir recursos e esforço significativo no desenvolvimento da tecnologia. Em outras situações, o mais comum é a licença exclusiva por campo de aplicação. Para decidir se a empresa tem potencial para implantar determinada tecnologia, os escritórios exigem a apresentação de um plano de negócios, com a definição de metas para atingir o mercado. Aspectos financeiros, tais como valor mínimo, taxa de royalties, custos de manutenção da patente e participação acionária, no caso das empresas start-up, são discutidos caso a caso, sempre por pessoal qualificado. Algumas universidades brasileiras, como a UFRJ, já dispõem de orientação mais formalizada. Outras, como a UNICAMP e a UFRGS, estão em processo final de discussão de uma política. No IPT, com maior tradição no tema, modelos de contrato, especialmente em projetos de parceria, são utilizados há mais tempo.

Na Fundação COPPETEC (UFRJ), os contratos contêm cláusulas de sigilo, negociadas caso a caso. Quando a tecnologia já foi desenvolvida pela COPPE, a patente é da universidade e se licencia a sua exploração. No caso de licença exclusiva, esta poderá ser por prazo determinado, comprometendo-se a universidade a não transferir, dentro do período acordado, a tecnologia objeto do convênio para outra empresa. Um novo desenvolvimento envolve negociação e, geralmente, a propriedade é 50\% da COPPE e 50\% da empresa que financiou o projeto. A COPPE compromete-se a manter a empresa informada, pelo prazo de cinco anos, de quaisquer aperfeiçoamentos nos processos de produção ou utilização do produto objeto daquele contrato. Em alguns casos, a patente poderá ser propriedade única e exclusiva da empresa que, por sua vez, compromete-se a ceder à universidade uma licença, sem ônus e não-exclusiva, dos resultados para serem utilizados em pesquisas ou para fins didáticos.

\subsection{POLÍTICA DE REMUNERAÇÃO AO PESQUISADOR E À EQUIPE RESPONSÁVEL PELAS AÇÕES DE TT.}

Esta é uma questão resolvida na maioria dos escritórios de TT das universidades estrangeiras, nos quais há claras políticas de investimento; manutenção de orçamentos adequados dos escritórios; compartilhamento de benefícios com os pesquisadores e funcionários, vista como importante ferramenta de estímulo aos inventores e funcionários do escritório, que compartilham interesses comuns. No Brasil, em função da legislação e da cultura organizacional, a remuneração aos profissionais envolvidos é o tópico mais complexo das discussões. Como, em geral, os escritórios não têm autonomia administrativa e financeira, não há estímulo à equipe para viabilizar os contratos de TT. Além disso, a estrutura administrativa das universidades, na qual a Consultoria Jurídica é centralizada, dificulta enormemente a decisão sobre conflitos em torno do que é questão de mérito e questão legal. As normas internas acompanham a resolução federal e estabelecem até $1 / 3$ dos benefícios financeiros da exploração comercial para os inventores. Na USP, por resolução interna anterior, os inventores recebem 50\% (www.usp.br). 


\section{CONCLUSÕES}

Este artigo examinou as atividades e o desempenho de alguns escritórios de transferência de tecnologia em universidades e institutos de pesquisa públicos, buscando entender os processos de gestão da propriedade intelectual dos resultados de pesquisa e seu conseqüente licenciamento e comercialização. Examinando essas características à luz da experiência internacional, observou-se, nos casos brasileiros, vários aspectos identificados como problemas a serem evitados. Os procedimentos recomendados pela literatura internacional e aqueles extraídos da análise dos casos de sucesso nacionais e internacionais são bastante apropriados para a situação brasileira. Assim, são apresentadas, a seguir, algumas sugestões para um melhor desempenho dos escritórios de transferência de tecnologia nacionais.

$\Rightarrow$ atuar junto aos órgãos governamentais, assessorando-os tecnicamente, participando das discussões e exigindo mudanças nos marcos regulatórios, no sentido de facilitar a parceria com a indústria.

$\Rightarrow$ Propor mudanças no âmbito interno das universidades, sugerindo diretrizes para transferência de tecnologia e estímulo aos pesquisadores e funcionários envolvidos.

$\Rightarrow$ Redefinir as estruturas administrativas e operacionais, no sentido de torná-las mais ágeis e aptas a operar no contexto da parceria com a empresa.

$\Rightarrow$ Investir na capacitação de recursos humanos com qualificações específicas, voltadas à negociação e comercialização de tecnologia e, ao mesmo tempo, investir em ações de sensibilização e valorização de atividades de transferência de tecnologia para a sociedade. Os escritórios devem contar com pessoal qualificado e especializado nas suas funções específicas (a propósito, difícil de encontrar nos quadros da universidade) e não apenas com professores e pesquisadores deslocados para essas funções.

$\Rightarrow$ Ampliar o fluxo de tecnologia para as empresas, estimulando projetos em parceria. Os escritórios não devem se ater à função de proteger o conhecimento gerado na universidade e tentar licenciá-lo para empresas. É preciso estimular a realização de projetos que tenham a participação de empresas desde o início, o que vai ao encontro de iniciativas governamentais como o Fundo Verde e Amarelo e o Programa PITE da FAPESP.

$\Rightarrow$ Promover a imagem positiva da universidade para conquistar espaço na agenda dos empresários e valorizar a pesquisa acadêmica. Esse processo envolve a elaboração de folhetos para distribuição externa e interna; a realização de palestras nas várias unidades e em associações de classe empresariais; o desenho de sites "amigáveis" no portal da universidade, com clara indicação do escritório de transferência de tecnologia, e demais ações que devem ser sugeridas por especialistas em marketing.

$\Rightarrow$ Incentivar a criação e a ampliação de incubadoras de base tecnológica e de empresas start-up como um caminho para a difusão do conhecimento gerado nas universidades e institutos de pesquisa.

$\Rightarrow$ Criar políticas específicas para estímulo a parcerias com pequenas empresas inovadoras. Sabe-se, pela experiência de projetos como o Disque Tecnologia, uma parceria da USP com o SEBRAE, que muitos pesquisadores acadêmicos não se interessam em colaborar com pequenas empresas, pois, em geral, os problemas que dificultam a inovação nessas empresas são relativamente simples, não constituindo um desafio intelectual para aqueles 
pesquisadores.

$\Rightarrow$ Elaborar manuais de procedimentos com critérios para a identificação de potenciais licenciados, definição de formas de licenciamento e modelos de contratos. Também elaborar apostilas com informações sobre métodos de valoração da tecnologia e de estudos de mercado para que a equipe de negociadores esteja preparada para, se necessário, colocar-se na perspectiva do cliente.

$\Rightarrow$ Elaborar manuais de orientação para negociadores, com análises de diferentes situações em que critérios financeiros, técnicos e sociais devem ser combinados. Sendo a valoração da tecnologia uma das principais deficiências dos escritórios, essa é uma atividade de suma importância. A empresa, na verdade, tem mais conhecimento sobre este tópico do que as universidades, mas não se deve negociar em condições desiguais de conhecimento. A assimetria de informações deve ser evitada a todo custo.

\section{REFERÊNCIAS}

ALLEN, D. Da descoberta à comercialização. Pesquisa Fapesp, São Paulo, n.50, p. 2-4, jan./fev. 2000. Encarte Especial Patentes.

AUTM. Homepage. Disponível em<http://www.autm.net>. Acesso em: 14 maio 2004.

BEN-AMI, P. Os riscos e as possibilidades de negócios. Pesquisa Fapesp. São Paulo, no. 50, p.5-7, jan./fev. 2000. Encarte Especial Patentes.

BEN-ISRAEL, R. Em contato direto com os pesquisadores. Pesquisa Fapesp. São Paulo, no. 50, p. 810, jan./fev.2000. Encarte Especial Patentes.

CHAMAS, C.I. Proteção e exploração econômica da propriedade intelectual em universidades e instituições de pesquisa. 2001. Tese (Doutorado).COPPE/UFRJ, Rio de Janeiro-RJ.

CHANG, Y. C. Why do some universities generate more patents and licensing incomes than others? The case of Taiwan. In: IAMOT Conference 2004. Washington, 2004.

COLORADO University Homepage. Disponível em: <http://www.txfr35.colorado.edu>. Acesso em 12 maio 2004.

CORNELL University Homepage. Disponível em <http://www.research.cornell.edu>. Acesso em 11 mai. 2004.

DAGNINO, R. A Relação Universidade-Empresa no Brasil e o "Argumento da Hélice Tripla". Revista Brasileira de Inovação, Rio de Janeiro, v.2, n.2, p. 267-307, jul./dez. 2003.

EMERICK, M.C. O resultado das estratégias das instituições brasileiras. Pesquisa Fapesp, São Paulo, no. 50, p. 11-14, jan./fev. 2000. Encarte Especial Patentes.

FUJINO, A.; STAL, E.; PLONSKI, G.A A proteção do conhecimento na universidade. Revista de Administração. São Paulo, v.34, n.4, p.46-55, out./dez.1999.

GOLDFARB, B. \& HENREKSON, M. Bottom-up versus top-down policies towards the commercialization of university intellectual property. Research Policy, v.32, p. 639-658, 2003. 
GRANOWITZ, J. Licenciamento para o setor privado. [Palestra proferida na Conferência Internacional Campinas Inova, Campinas, 18-19 de Março, 2004]

GREGORIO, D.I. \& SHANE, S. Why do some universities generate more start-ups than others? Research Policy, v.32, n.1, p. 209-227, jan. 2003.

JOHNS HOPKINS University. Homepage. Disponível em <http://www.hopkinsmedicine.org/lbd/otl>. Acesso em: 31 mar.2004.

JORNAL DA CIÊNCIA. Análise dos especialistas sobre a lei de inovação. JC e-mail 2370, de 23 de setembro de 2003. Disponível em <http://www.jornaldaciencia.org.br>. Acesso em : 24 set.2003.

KAMIJO, Y. \& WATANABE, T. Intellectual property management of university intellectual property headquarters in Japan, IAMOT Conference 2004. Washington, 2004.

UNIVERSITY OF MARYLAND . Homepage. Disponível em <http://www.ord.umaryland.edu>. Acesso em: 31 mar. 2004.

MATKIN, G.W. Technology Transfer and the University. New York: American Council on Education/MacMillan Publ.,, 1990. 329 p.

MASSACHUSETTS INSTITUTE OF TECHNOLOGY. Homepage. Disponível em <http://www.mit.edu/tlo/www/guide.toc.html>. Acesso em : 31 mar. 2004.

PARK, J-B. Public-to-private technology transfer system in Korea: the case of the regional consortium of technology licensing offices. In: IAMOT Conference 2004. Washington, 2004.

PITKETHLY, R.H. Intellectual property strategy in Japanese and UK companies: patent licensing decisions and learning opportunities. Research Policy, v.30, p.425-442, 2001.

PRIES, F. e GUILD, P. Analysing the commercialization of university research: a proposed categorization scheme. In: IAMOT Conference 2004. Washington, 2004.

REINACH, F. Capital de risco: uma questão crítica. Campinas Inova, mar. 2004.

REITZIG, M. What determines patent value? Insights from semiconductor industry. Research Policy, v.32, n.1, p.13-26, jan.2003.

SHANE, S. Executive forum: university technology transfer to entrepeneurial companies. Journal of Venturing, v. 17 p.537-552, 2002.

SHERRY, E.F.; TEECE, D.J. Royalties, evolving patent rights, and the value of innovation. Research Policy, v.33. p. 179-191, 2004.

SIEGEL, D.S. et al. Commercial knowledge transfers from universities to firms: improving the effectiveness of university-industry collaboration. The Journal of High Technology Management Research, v.14, no. 1, p. 111-133, Spring, 2003.

SIEGEL, D.S, WALDMAN, D., LINK, A. Assessing the impact of organizational practices on the relative productivity of technology transfer offices: an exploratory study. Research Policy, v.32, n.1, p.27-48. jan.2003.

STAL, E. A contratação empresarial da pesquisa universitária. Revista de Administração ,São Paulo, v.30, n.1, p.3-18, jan.-mar.1995. 
STAL, E. e SOUZA NETO, J. Cooperação institucional universidade-empresa. Porto Alegre-RS: SEBRAE, 1998.

STANFORD University. Homepage. Disponível em <http://www.portfolio.stanford.edu>. Acesso em: 14 maio 2004.

TAMAI, K. \& NISHIMURA, Y. Successful model of technology transfer from university to industry in Japan. IAMOT 2004. Washington, 2004.

THURSBY, J.G. e THURSBY, M.C. University Licensing and Bay- Dole Act. Science, v.22. p.301, Aug., 2003.

UFRGS. Homepage. Disponível em <http://www.ufrgs.br>. Acesso em: 24 abr. 2004.

UFSCAR. Homepage. Disponível em <http://www.ufscar.br> Acesso em: 23 abr. 2004.

UNICAMP. Homepage. Disponível em <http://www.unicamp.br>. Acesso em 23 abr.2004.

UNIFESP. Homepage. Disponível em <http://www.unifesp.br>. Acesso em: 24 abr. 2004.

USP. Homepage. Disponível em <http://www.usp.br>. Acesso em: 24 abr. 2004.

VALENTÍN, E.M.M. A theorethical review of co-operative relationships between firms and universities. Science and Public Policy, p. 37-46, Feb. 2002.

WATANABE, T. et al. Vizualizing the invisible: a marketing approach of the technology licensing process. IAMOT 2004. Washington, 2004.

YISSUM Homepage. Disponível em <http://www.yissum.co.il>. Acesso em: 11 mai. 2004.

YU, A.S.O. \& AZEVEDO, P.B.M Análise de investimento em tecnologia: a experiência da Divisão de Economia e Engenharia de Sistemas do Instituto de Pesquisas Tecnológicas. Revista de Administração, São Paulo, v.35, n.4. p. 103-118, out./dez. 2000.

\title{
MANAGEMENT OF THE INTELECTUAL PROPERTY BY THE BRAZILIAN PUBLIC UNIVERSITY: GUIDLINES FOR LICENSING AND COMMERCIALIZATION.
}

\begin{abstract}
This article discusses the management of intellectual property in Brazilian public universities, mainly in relation to strategies for commercialization or licensing the results of academic research. It identifies, in the international literature, the main strategies adopted and recommended by technology transfer offices in foreign universities, and compares them to the practices adopted in different Brazilian universities. Finally, it makes recommendations to enhance the procedures adopted by Brazilian institutions.
\end{abstract}

Key words: Patent. Technology transfer offices. Commercialization. Licensing. Public university. Results of academic research.

Submissão: abril de 2006

Aceite: setembro de 2006 